\title{
The Research of the role of College Physical Education in College Students' Mental Health and Education
}

\author{
Qiang HUANG \\ Chengdu University of Information Technology \\ Chengdu,Sichuan,610225 China
}

\begin{abstract}
On the basis of in-depth analysis of the meaning of the Mental Health, the thesis analyzed that the important role of college physical education in promoting college students' mental health. Also, it is suggested some very important issues for college physical education throughout the mental health education: the main factors affecting the mental health of college students; the way of college physical education promoting mental health; physical education as an important means of mental health education.
\end{abstract}

Keywords- College physical education, mental health, role

\section{INTRODUCTION}

College Sports and mental health education are important contents of quality education, both of which have close ties. Mental health is an important standards for the concept of modern health, and the purpose of college sports teaching is to implement the "health first" thinking. As an important part of higher education, college sports not only have the teaching task of fitness, but also bear important responsibilities from the health of the heart. So, how to use the unique features of college sports on college students' mental health, solve the problem of college students' mental health as much as possible become an important issue for today's college physical education workers.

\section{THE CONCEPT OF MENTAL HEALTH}

Mental health is a multi-dimensional, three-dimensional concept which has been related to the content of biology, psychology and sociology. Mental health refers to personal mental state can be developed to the best within the scope that the physical, emotional, intelligential aspects of one person do not contradict with the mental health with others. In 1989, United Nations World Health Organization has proposed a new concept of health in the 21st century: "Health is not just the absence of disease, but includes physical health, mental health, social well-adapted and moral health." In 21st century, people's health is the perfect integration of physical, psychological social adaptation and moral health.

\section{MAIN FACTORS AFFECTING THE MENTAL HEALTH OF COLLEGE STUDENTS}

\section{A. Inadaptation of university study and life suited}

University life is different from secondary school, can be said to be a new way of learning, thinking, and even transition of lifestyle. Exam-oriented education and cramming schools have been transformed into self-oriented teaching, learning methods, supplemented by instructor, conscious, self-reliance, self-learning are the main characteristics of university, some students after entering the university failed to grasp the learning methods in university, resulting in exams defeat, leading to weariness, self-esteem, self-confidence and a series of psychological decline problems.

\section{B. Inappropriate way of Family Education}

Many parents count on not only their own children to go to the college, study abroad, more to win glory for the family. However, parents' high expectations will create students heavy psychological burden, easy to a prone to low selfesteem, irritable mood when facing difficulties.

\section{The stress of real-life}

From the perspective of the development of individual psychology, college students are in self-confirmation period, in their mind they will design a better future. However, the various social objective barriers in the society often impede the achievement of "ideal self". In recent years, more and more colleges and universities extended range, often making huge competitive pressures on graduate employment.

\section{Situation OF Mental Health Problems}

\section{A. Life issues}

Life after school freshmen adaptation, college students before entering college are dedicating to learn. After entering the university, in all aspects of self-awareness, classmates and natural environment are faced with a comprehensive adjustment and adaptation, the performance lost and dazed. Among them, there are two kinds of psychological problems such freshmen most likely to occur: First, not voluntary but students enrolled; Second, students with low test scores, because in high school do not have to lay the foundation, into 
the school cannot adapt to the new learning environment prone to mental weariness and anxiety.

\section{B. Maladaptive interpersonal relationship}

The quality of individual relationship can have a significant psychological effect. Due to cognitive factors, emotional factors, personality factors, not every college student can better handle relationships. Some students in the event of interpersonal frustration, it is possible to self-denial, and fall into depression, anxiety, and some even get into predicament because of attempting to fight.

\section{Strong Emotion but unstable}

College students are at a crucial stage of emotional development, they have rich emotion, deeply emotional experience, delicate, but because experience is shallow, emotion is not stable enough, they can be easily agitated, irritable. On the other hand, since the majority of students away from their parents, and in adolescence, ages close to each other, prone to exchange of ideas and feelings, but due to the lack of life experience, poor self-control, relatively weak willpower, they simplify love, do not consider consequences of acts.

\section{WAys OF COLLEGE PhysicAl EdUCATION TO PROMOTE MENTAL HEALTH}

\section{A. Emphasis on the institutional level}

Establishment of the Physical Education and physical health, mental health unity of physical education curriculum teaching system, confirmation of the objective of college physical education, is not just education of body and skills, but also includes mental health education, and undertake the important task of cultivating healthy and harmonious modern civilized talents adapting to modern society and culture economic development.

\section{B. Fully understand the psychological characteristics of college students}

Implementing mental Health Education in physical education, physical education teachers should effectively understand the personality characteristics, hobbies, sports skills and physical condition of college students, be aware of the teaching content varies from different students throughout the teaching, in daily physical education, there should have purposeful, conscious psychological impact on students so that they can withstand victory, defeat, frustration, suffering and other tests to improve their endurance and selfcontrol ability, through certain measures to enhance their self-confidence, hone their will, and promote the full development of his personality at the same time, we should fully trust and respect the students, providing more freedom to develop and strengthen their self-awareness, mobilize their enthusiasm, to cultivate good competitive awareness and promote the development of students' psychological health.

\section{To diversify sports extracurricular activities}

Conducting various forms of sports extracurricular activities in physical education course, can be combined with classroom Physical Education to achieve dual function of heart health and physical fitness. In physical education curriculum, we can take a combination form of classroom, extracurricular teaching, organize students to participate in a variety of extracurricular sports activities, such as mountain climbing, tug of war, basketball games and other sports activities, not only to enrich students' spare time, but also to establish a good relationship between teachers and students in the process of participation.

\section{PHYSICAL EDUCATION IS AN IMPORTANT MEANS OF MENTAL HEALTH EDUCATION}

\section{A. Different sports teaching methods have different effects on mental health}

Small groups mutual learning method, can strengthen the sense of responsibility, creativity, collaboration awareness, foster a sense of competition, and greatly contribute to the establishment of good relationships between students. Simulation training and ideas training method can improve students' self-control, self confidence, improve mental ability to adapt and adjust. Create situations method, can stimulate students' interest and emotion to get a positive feeling and understanding, have a positive inner experience, and ultimately turn into the cognitive structure, cultivate the idea with good quality.

\section{B. Different sports teaching methods produce different effects on students' psychological}

Mental Health Physical Education of college students emphasizes the change of the background environment, improves their mental interference ability and viability, strengthens the role and status of interactivity to develop their organizational skills, adaptability and interpersonal ability, the use of sex effect organizational practice, so that students in front of the opposite sex can suppress their bad behavior. Promote good ideological quality, healthy culture and develop their personality, to introduce competition sports competition, to stimulate students' interest and achievement motivation. This will help students develop positive spirit and sense of competition, to improve their sense of independence and ability.

\section{THE ROLE OF COLLEGE PHYSICAL EDUCATION IN PROMOTING MENTAL HEALTH OF COLLEGE STUDENTS}

\section{A. Penetrating physical health and mental health are equally important ideas from PE class}

Mental health is an important indicator of college which can be moving in a positive upward direction, and are equally important with physical health. College sports is to develop physical and mental health harmoniously. College Sports classroom teaching, gradually penetrates mental health education, and takes psychological education as one 
of the goals of the curriculum, effectively improving the mental health of college students, improving the quality of the sport, but also led to the coordinated development of students' psychological health. college students as a group having weak mental capacity, easily get emotional fluctuations, the probability of the loss of balance from outside influence is also great, therefore, mental Health Education in college Physical Education is very necessary and effective.

\section{B. Confidence}

College sports programs can inspire students to develop their potential athletic potential, and help students establish self-confidence. Students in the different sports, to find space for their play, can help college students make a correct assessment of their own, improve the ability of psychological adjustment, and self-confidence, so that college sports programs can also promote the cultivation of students' psychological health. The conduct of college physical education, effectively improves the college students' emotional ability to debug their emotion, so that students' resilience and resisting ability has improved significantly.

\section{To promote the development of self-awareness}

Sport helps students to understand themselves. Most collective sport, competitive activity, the level of their ability, accomplishment is good or bad, charm size will obviously manifested so that one will have a more realistic selfawareness. Sport also helps self-education. On the basis of self-understanding, the students will consciously or unconsciously modify their knowledge and behavior, develop and improve the quality and capabilities to meet social psychological needs, to become more in line with the needs of society, and adapt to the social environment.

\section{Sports can cultivate good will}

Sports generally have a hard, fatigue, intense, intense confrontation and competition and strong features, when the students participate in physical exercise, always accompanying by a strong emotional experience and a clear will. Thus, sport can help students to have ideological style of brave ,tenacious, hard-working, perseverant, and overcoming difficulties, helps to develop solidarity, collectivism and patriotism, help to develop quick and clever, calm and decisive, willpower modest, so that students can maintain a positive and healthy mental state.

\section{E. Sport can promote physical development, provide firm material basis for mental health development}

Mentality is the organism of human brain, the human brain is a part of the human body. Mental health development should be based on normal body as the material basis. Through sport, to promote normal, healthy development of the body, providing a solid material foundation for the mental development. This is an important condition for mental development.

\section{F. Physical Education affects emotional development of students}

Diversity, attractiveness, complexity, entertainment and variability of sports teaching contents can make a person to experience satisfaction, happy, joy, nervousness, excitement, anxiety and so many different levels of emotional experience. Groups and interactive sport teaching activities can inspire students' social awareness, enhance self-esteem, selfconfidence and sense of responsibility, and competition can stimulate students' initiative, encouraging their will.

\section{G. Physical Education affects cognitive development of students}

Physical Education with intuitive features, require students to use a variety of related integrated sensory organs, not only through visual, auditory perception of the image of the action, but also to perceive the essentials of the action and muscle force degree by tactile feeling and muscular feeling, as well as the relationship between time and space in the course of action, so as to establish a complete, correct action representation. In this process, the students' perception, observation and image memory, movement and memory etc. can be developed and improved.

\section{$H$. Enhance the anti-pressure ability of college students}

College students in today's society face pressure from all sides, both school academic pressure on them, but also from the responsibility of their parents, more pressure on social employment, and all kinds of pressures sticking together for college students have become an insurmountable barriers, under these pressures, the mental state of college students is difficult to maintain at a good level. General mental health education courses does not provide practice environment for students to face the pressure, so that students' ability to enhance the anti-pressure ability just stays on the theoretical level. Then the college Physical Education can make up deficiencies of college mental Health Education, by providing a highly competitive platform to enhance the antipressure ability for college students, in a real environment to feel the process of pressure appears and pressure relieves, to enhance students' ability to solve problem, so that students dare to face difficulties. Therefore, college Physical Education provides students with a platform to improve antipressure ability, so that students can be positive when facing pressure, which is bound to promote to form a good mental state for college students.

\section{CONCLUSION}

Mental health state for college students is not optimistic, which attracted the attention of the community. College Physical Education as the unique education activities to shape healthy quality of college students should fully play its role. Facing with these reality requirements, college sports education system should be run through mental health education from beginning to end. This has an important role in improving college students' cognitive abilities, improving and easing the emotional and psychological state of college 
students, and enhancing college students' ability and skills to adapt to the society.

\section{REFERENCES}

[1] Zhengxuemei . Impact on the mental health of college sports college studies [D]. Sichuan University, 2006.

[2] JU Lingling. Korfball movement of mental health of college students Experimental Study [D]. Hebei Normal University, 2012.
[3] Lei Jun. College Ph ysical Education Students' Mental health educational role. [J]. Technological horizon, 2014,05:118.

[4] Song Hangguo. Promote Physical Education of College Students' Mental Health [J]. Guangdong Technical Teachers College,2009,12:90-93.

[5] Physical education teaching impact on the mental health of college

[6] Liu Bo. students and Countermeasures [J]. Intelligence, 2014,02:68.

[7] Yang Lili. Influence of College Physical Education on Mental Health of College Students [J]. Sport,2012,22:86-87. 